\title{
ANALISIS PERBANDINGAN NILAI KOEFISIEN PERMEABILITAS TANAH UJI LAPANGAN DAN UJI LABORATORIUM
}

\author{
Philip Chen ${ }^{1}$ dan Gregorius Sandjadja Sentosa ${ }^{2}$ \\ ${ }^{1}$ Program Studi Sarjana Teknik Sipil, Universitas Tarumanagara, Jl. Letjen S. Parman No.1 Jakarta \\ philipchen96@gmail.com \\ ${ }^{2}$ Program Studi Sarjana Teknik Sipil, Universitas Tarumanagara, Jl. Letjen S. Parman No.1 Jakarta \\ gregorius@ft.untar.ac.id
}

Masuk: 17-01-2020, revisi: 16-02-2020, diterima untuk diterbitkan: 17-02-2020

\begin{abstract}
The coefficient of permeability $(k)$ results of pumping tests are used as initial data to determine the rate of water seepage in the soil, determining the permeability capability of the soil can be done by measurements in the laboratory and in the field. In reality the permeability coefficient value of field test is not the same as the test in the laboratory. This final project will analyze the difference in value $(k)$ obtained from field and laboratory tests in order to enrich the data in determining the value of permeability coefficient $(k)$. The analysis uses Thiem and Theis method in analyzing the results of pumping tests. And using constant head permeameter to determine the value of the coefficient of permeability $(k)$ in laboratory. From the analysis results obtained by the Thiem method, the permeability coefficient $(k)$ obtained is in the range of $6,8 \times 10^{-2} \mathrm{~cm} / \mathrm{sec}-2,8 \times 10^{-2} \mathrm{~cm} / \mathrm{sec}$, and Theis method is obtained in the range of $6,03 \times 10^{-2} \mathrm{~cm} / \mathrm{sec}-6,03 \times 10^{-3} \mathrm{~cm} / \mathrm{sec}$. Meanwhile the results of the coefficient of soil permeability $(k)$ by the laboratory tests using the constant head permeameter is in the range $1,43 \times 10^{-4} \mathrm{~cm} / \mathrm{sec}-$ $8,76 \times 10^{-7} \mathrm{~cm} / \mathrm{sec}$. And for calculations using the Hazen method the result is in the range $8,71 \times 10^{-6} \mathrm{~cm} / \mathrm{sec}-$ $4,35 \times 10^{-6} \mathrm{~cm} / \mathrm{sec}$.
\end{abstract}

Keywords: Pumping Test; Koefisien Permeabilitas Tanah; Metode Thiem; Metode Theis; Constant Head

\begin{abstract}
ABSTRAK
Nilai koefisien permeabilitas (k) hasil pumping test digunakan sebagai data awal untuk mengetahui kecepatan rembesan air di dalam tanah, penentuan kemampuan permeabilitas tanah dapat dilakukan dengan pengukuran di laboratorium dan di lapangan. Dalam kenyataannya nilai koefisien permeabilitas uji lapangan biasanya tidak sama dengan uji di laboratorium. Penelitian ini akan menganalisa perbedaan nilai (k) yang didapat dari uji lapangan dan uji laboratorium guna memperkaya data dalam menentukan nikai koefisien permeabilitas (k). Analisa pada penelitian ini menggunakan metode Thiem dan metode Theis dalam menganalisa hasil pumping test pada lapangan. Dan menggunakan constant head permeameter sebagai alat menentukan nilai koefisien permeabilitas (k) pada laboratorium. Serta menggunakan metode rumus empiris Hazen untuk menentukan nilai koefisien permeabilitas (k) berdasarkan ukuran butiran. Dari hasil analisis yang diperoleh dengan metode Thiem nilai koefisien permeabilitas (k) yang didapat berada pada rentang $6,8 \times 10^{-2} \mathrm{~cm} /$ detik $-2,8 \times 10^{-2} \mathrm{~cm} /$ detik, dan dengan metode Theis didapat pada rentang $6,03 \times 10^{-2} \mathrm{~cm} /$ detik - $6,03 \times 10^{-3} \mathrm{~cm} /$ detik. Sedangkan hasil uji laboratorium menggunakan permeameter constant head mendapatkan hasil nilai koefisien permeabilitas tanah $(\mathrm{k})$ pada rentang $1,43 \times 10^{-4}$ $\mathrm{cm} /$ detik - $8,76 \times 10^{-7} \mathrm{~cm} /$ detik. Dan didapat hasil $8,71 \times 10^{-6} \mathrm{~cm} /$ detik $-4,35 \times 10^{-6} \mathrm{~cm} /$ detik untuk perhitungan menggunakan metode Hazen.
\end{abstract}

Kata kunci: Pumping Test; Koefisien Permeabilitas Tanah; Metode Thiem; Metode Theis; Constant Head

\section{PENDAHULUAN}

Pumping test adalah sebuah metode pengendalian dan juga sebagai metode kontrol pada proses dewatering atau berguna untuk menentukan nilai koefisien permeabilitas $(k)$. Hasil pumping test ini digunakan sebagai data awal untuk mengetahui kecepatan rembesan air di dalam tanah, Penentuan kemampuan permeabilitas tanah dapat dilakukan dengan pengukuran di laboratorium dan di lapangan. Dalam kenyataan nya nilai koefisien permeabilitas uji lapangan biasanya tidak sama dengan uji di laboratorium. Penelitian ini akan mengkaji perbedaan nilai $(k)$ yang didapat dari uji lapangan dan uji laboratorium. 
Lokasi pelaksanaan pumping test ini berada di Jakarta Timur. Pumping test dilakukan selama 96 jam (aktual yang dilakukan adalah mencapai +5780 menit). Ada dua macam sumur yang digunakan dalam pumping test ini yaitu sumur yang akan dipompa (pumping well) sebanyak 1 buah dan sumur pengamatan (observation well) sebanyak 7 buah. Pumping well tersebut memiliki kedalaman $20 \mathrm{~m}$, konstruksinya menggunakan pipa PVC berdiameter 6". Observation well pada pumping test ini memiliki kedalaman $13 \mathrm{~m}$ dan menggunakan konstruksi pipa PVC berdiameter 2". Pompa yang digunakan untuk melakukan pumping test ini menggunakan pompa berjenis submersible dengan kapasitas terpasang $100 \mathrm{~L} /$ menit - $300 \mathrm{~L} /$ menit. jenis akifer yang terdapat pada lokasi pumping test adalah berjenis akifer tertutup. Didalam kondisi akifer tertutup ini dapat digunakan dua metode perhitungan yaitu Metode Thiem (steady state) dan Metode Theis (unsteady state).

Sampel yang tersedia untuk uji di laboratorium kondisinya tidak cocok dengan uji permeabilitas tekanan tetap ASTM 2434 (2006) constant head permeabilty test, karena ukuran butir yang melebihi saringan no.200 lebih dari $10 \%$. Disamping itu alat yang tersedia juga tidak sesuai dengan standar yang disebutkan oleh ASTM 2434 yaitu diameter alat tidak sesuai, alat tidak dilengkapi dengan alat vakum untuk mengeluarkan udara dari air. Selain itu karena ukuran butir yang melewati saringan no.200 melebihi 10\% (ukuran butir halus) maka pengujian harus dilakukan menggunakan metode falling head yang belum ada standar baku ASTM maupun standar lainnya. Mengingat kondisi keterbatasan tersebut di atas, maka uji laboratorium yang dilakukan adalah dengan uji constant head yang dimodifikasi sedemikian rupa yang mungkin hasilnya tidak dapat mencapai kondisi ideal.

Uji coba dilakukan di laboratorium menggunakan permeameter constant head. Sampel tanah diambil dari lokasi yang sama dari lokasi pumping test untuk dilakukan uji coba di laboratorium. Sampel tanah yang digunakan berasal dari kedalaman 13m-14m pada lokasi BH14(lanau kelempungan) dan BH15(pasir halus kelanauan). Dua lokasi tersebut yaitu BH14 dan BH15 dianggap memberikan pengaruh banyak terhadap hasil pemompaan. Pengukuran nilai koefisien permeabilitas $(k)$ di laboratorium dilakukan dengan merekayasa berat volume tanah $(\gamma)$. Rekayasa tersebut diharapkan dapat mewakili kondisi asli seperti dilapangan. Masing-masing lokasi BH14 dan BH15 pada kedalaman $13 \mathrm{~m}-14 \mathrm{~m}$, diuji dengan menggunakan parameter berat volume $\gamma_{\min }, \gamma, \gamma_{\max }$. Berat volume ( $($ ) digunakan sebagai parameter karena dengan menggunakan nilai berat volume $(\Upsilon)$ maka kepadatan relatif $(D r)$ dapat ditentukan. Dengan diketahuinya kepadatan relatif $(D r)$ nilai N-SPT dilapangan menjadi batasan dalam menentukan kepadatan tanah di laboratorium. Dengan adanya batasan tersebut diharapkan kepadatan tanah di laboratorium dapat mewakili kondisi kepadatan tanah asli lapangan. Uji permeabilitas constant head masing masing dilakukan uji coba sebanyak dua buah sampel untuk $\gamma_{\min }, \gamma, \gamma_{\max }$.

\section{Analisis pumping test akifer tertutup metode Thiem (steady state)}

Akifer tertutup adalah akifer jenuh air yang diapit oleh lapisan tanah yang kedap air(Aquiclude). Tekanan air dalam akifer tertutup biasanya lebih besar dari tekanan atmosfir. Air yang terkandung dalam akifer iní disebut sebagai air tertutup atau air artesis yang akan memancar keluar melalui sumur-sumur artesis atau mata air. Metode Thiem (1906) digunakan pada kondisi akifer tertutup dan dalam keadaan setimbang (steady state). Metode ini menggunakan dua buah piezometer atau lebih yang ditempatkan dekat dengan sumur pompa agar dapat memberikan hasil pengujian yang baik. Skema pemompaan pada akifer tertutup dapat dilihat pada gambar 1 .

Debit air yang dipompa dapat dihitung dengan rumus :

$$
\mathrm{Q}=\frac{2 \pi k D\left(S_{m 1}-S_{m 2}\right)}{2.3 \log \left(\frac{r_{2}}{r_{1}}\right)}
$$

Dengan $\mathrm{Q}=$ debit pemompaan $\left(\mathrm{m}^{3} /\right.$ hari atau $\mathrm{m}^{3} /$ menit $), \mathrm{k} \mathrm{D}=\mathrm{T}=\operatorname{transmisivitas}$ akifer $\left(\mathrm{m}^{2} / \mathrm{hari}_{\text {atau }} \mathrm{m}^{2} /\right.$ menit), $\mathrm{k}=$ permeabilitas tanah $(\mathrm{m} /$ hari atau $\mathrm{m} / \mathrm{menit}), \mathrm{D}=$ ketebalan akifer $(\mathrm{m}), \mathrm{r}=$ jarak sumur pantau (piezometer) dari sumur pompa $(\mathrm{m}), \mathrm{Sm}=$ drawdown saat kondisi setimbang pada sumur pantau $(\mathrm{m})$, indeks 1 dan 2 menunjukkan sumur pantau pertama dan kedua. 


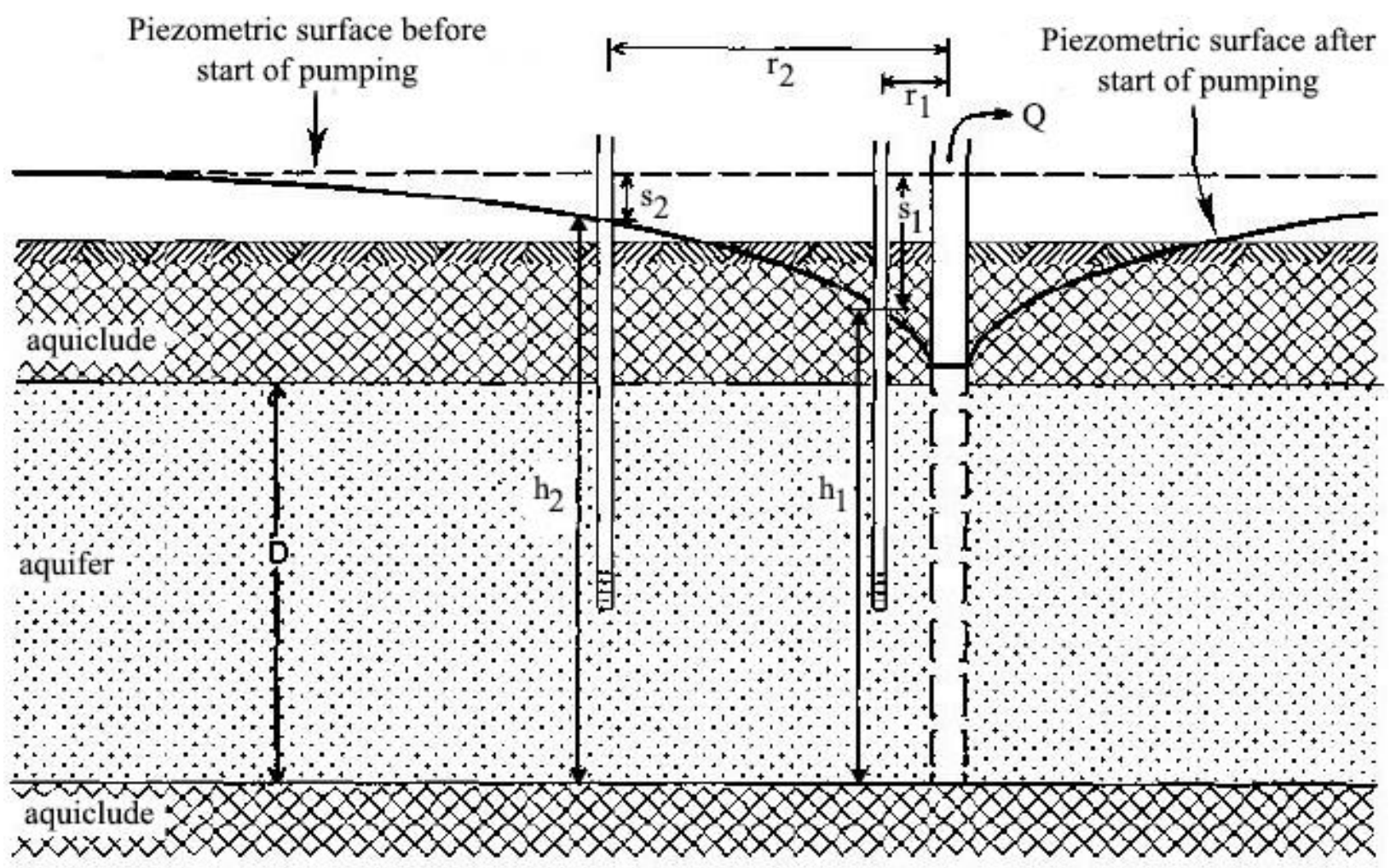

Gambar 1. Skema pemompaan akifer tertutup (Sumber: Kruseman, 2000)

\section{Analisis pumping test akifer tertutup metode Theis (unsteady state)}

Metode Theis (Theis, 1938) berlaku untuk akifer tertutup yang alirannya berada dalam keadaan tidak setimbang (unsteady state). Keadaan tidak setimbang adalah perubahan drawdown bersama berlalunya waktu tidak dapat diabaikan. Terdapat beberapa asumsi yang dicetuskan oleh Thies, yaitu bahwa saat sebuah sumur menembus akuifer tertekan yang luas dan dipompa dengan debit konstan, pengaruh debit meluas keluar seiring dengan waktu. rumus yang digunakan adalah :

Dan

$$
\mathrm{W}(\mathrm{u})=-0,5772-\ln \mathrm{u}+\mathrm{u}-\frac{u^{2}}{2.2 !}+\frac{u^{3}}{3.3 !}
$$

$$
\mathrm{K} \mathrm{D}=\frac{Q}{4 \pi S_{A}} \mathrm{~W}(\mathrm{u})
$$

Dengan $\mathrm{Q}=$ debit pemompaan $\left(\mathrm{m}^{3} /\right.$ hari atau $\mathrm{m}^{3} /$ menit $), S_{A}=$ koordinat pembacaan match point, Cs $=$ koefisien penyimpanan (tidak berdimensi), $\mathrm{t}=$ waktu (menit atau hari) sejak pemompaan dimulai, $\mathrm{s}=$ penurunan muka air tanah selama pemompaan $(\mathrm{m}), \mathrm{r}=$ jarak piezometer dari sumur pompa $(\mathrm{m}), \mathrm{k}=$ permeabilitas tanah $(\mathrm{m} / \mathrm{hari}$ atau $\mathrm{m} / \mathrm{menit}), \mathrm{D}=$ ketebalan akifer $(\mathrm{m})$. Kurva tipikal Theis dapat dilihat pada gambar 2. 


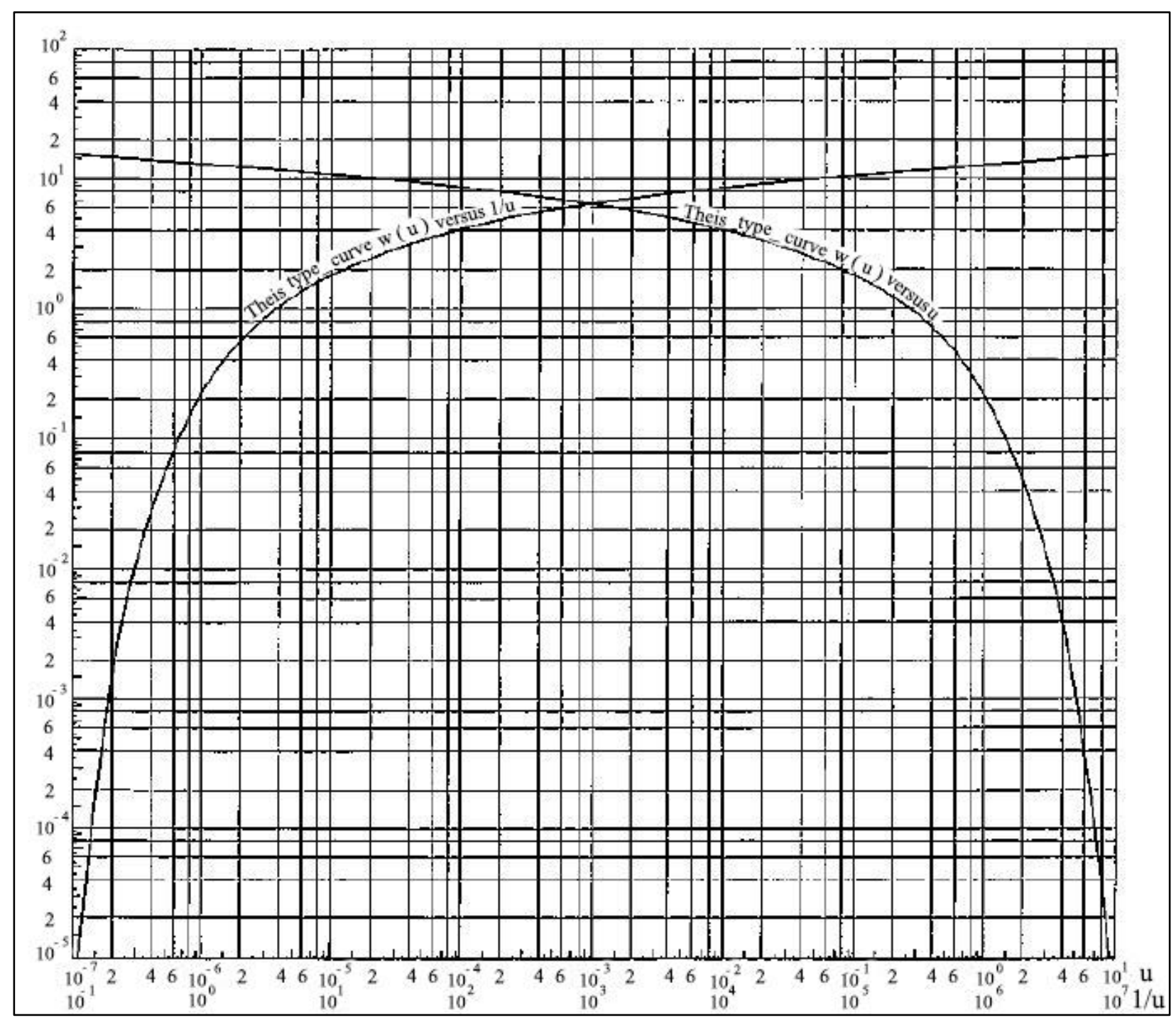

Gambar 2. Kurva Theis untuk W(u) versus U dan W(u) versus 1/u (Sumber: Kruseman, 2000)

\section{Constant head permeameter}

Cara yang dilakukan pada percobaan ini adalah air yang ada pada permeameter dengan tinggi tekanan yang tetap dibiarkan untuk mengalir menembus suatu sampel tanah yang telah dimasukkan kedalam sebuah silinder yang memiliki luas penampang(A) (Das, 2008). Kemudian banyaknya debit air (Q) yang lewat melalui sampel tanah tersebut diukur dalam satuan waktu (t) dan kemudian air yang berhasil melewat sampel tanah tersebut dikumpulkan kedalam suatu gelas ukur. Piezometer yang dipasang pada silinder tersebut memperlihatkan tinggi tekanan (h) pada panjang sampel (L). Maka dari percobaan tersebut permeabilitas tanah dapat dihitung berdasarkan banyaknya air yang merembes melalui tanah dalam waktu tertentu, yang dirumuskan dalam hukum Darcy (Hubbert, 1957), yaitu:

$$
k=\frac{Q . L}{A . h . t}
$$

Dengan $Q=$ banyaknya air yang mengalir atau debit air $\left(\mathrm{cm}^{3}\right), A=$ luas penampang tanah yang dilewati oleh air $\left(\mathrm{cm}^{2}\right), t=$ waktu pengaliran $(\mathrm{dt}), k=$ koefisien permeabilitas tanah $(\mathrm{cm} / \mathrm{dt}), h=$ tinggi energi hidrolik melewati tanah $(\mathrm{cm}), L=$ panjang jalan aliran melalui tanah $(\mathrm{cm})$. Sketsa alat Constant Head Permeameter dapat dilihat pada gambar 3 . 


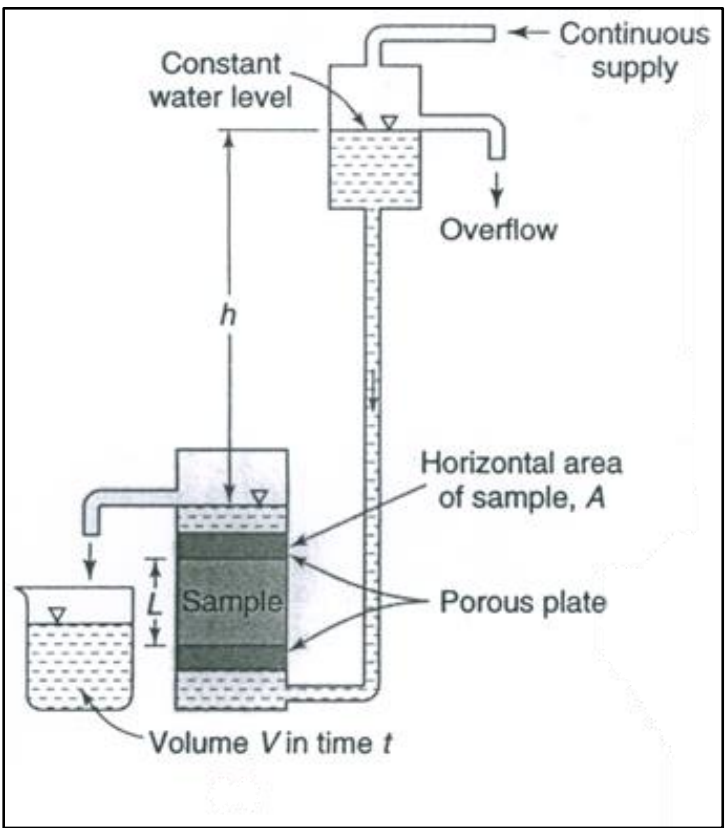

Gambar 3. Constant head permeameter (Sumber: Mays, 2012)

\section{Metode pendekatan empiris Hazen}

Hazen mengemukakan sebuah persamaan empiris yang menghubungkan permeabilitas dengan ukuran butir efektif $\left(\mathrm{D}_{10}\right)$ dari suatu analisa saringan (Bowles, 1979). Pasir dengan ukuran 0.1 sampai $3 \mathrm{~mm}$ koefisien permeabilitasnya dapat dihitung dengan rumus berikut :

$$
\mathrm{k}=\mathrm{Cx}\left(D^{2}{ }_{10}\right)
$$

Dengan $\mathrm{k}=$ koefisien permeabilitas tanah $\left(\mathrm{cm} /\right.$ detik), $\mathrm{D}_{10}=$ ukuran butir efektif $(\mathrm{cm}), \mathrm{C}=$ nilai koefisien berkisar antara 40 sampai 150 .

Tabel 1. Nilai C

\begin{tabular}{cc}
\hline $\mathrm{C}$ & Pasir \\
\hline $40-80$ & Very fine, well graded \\
\hline $80-120$ & Medium coarse, poorly graded $;$ clean, coarse but well graded \\
\hline $120-150$ & Very coarse, very poorly graded, gravelly, clean \\
\hline (Sumber: Bowles, 1979)
\end{tabular}

\section{METODOLOGI PENELITIAN}

Penelitian diawali dengan melakukan studi terhadap uji lapangan (pumping test) dan uji laboratorium (constant head permeability test). Setelah dilakukan studi, dilakukan pengumpulan data lapangan dan data laboratorium. Kemudian data diolah dan hasilnya dibandingkan untuk didapatkan kesimpulan. 


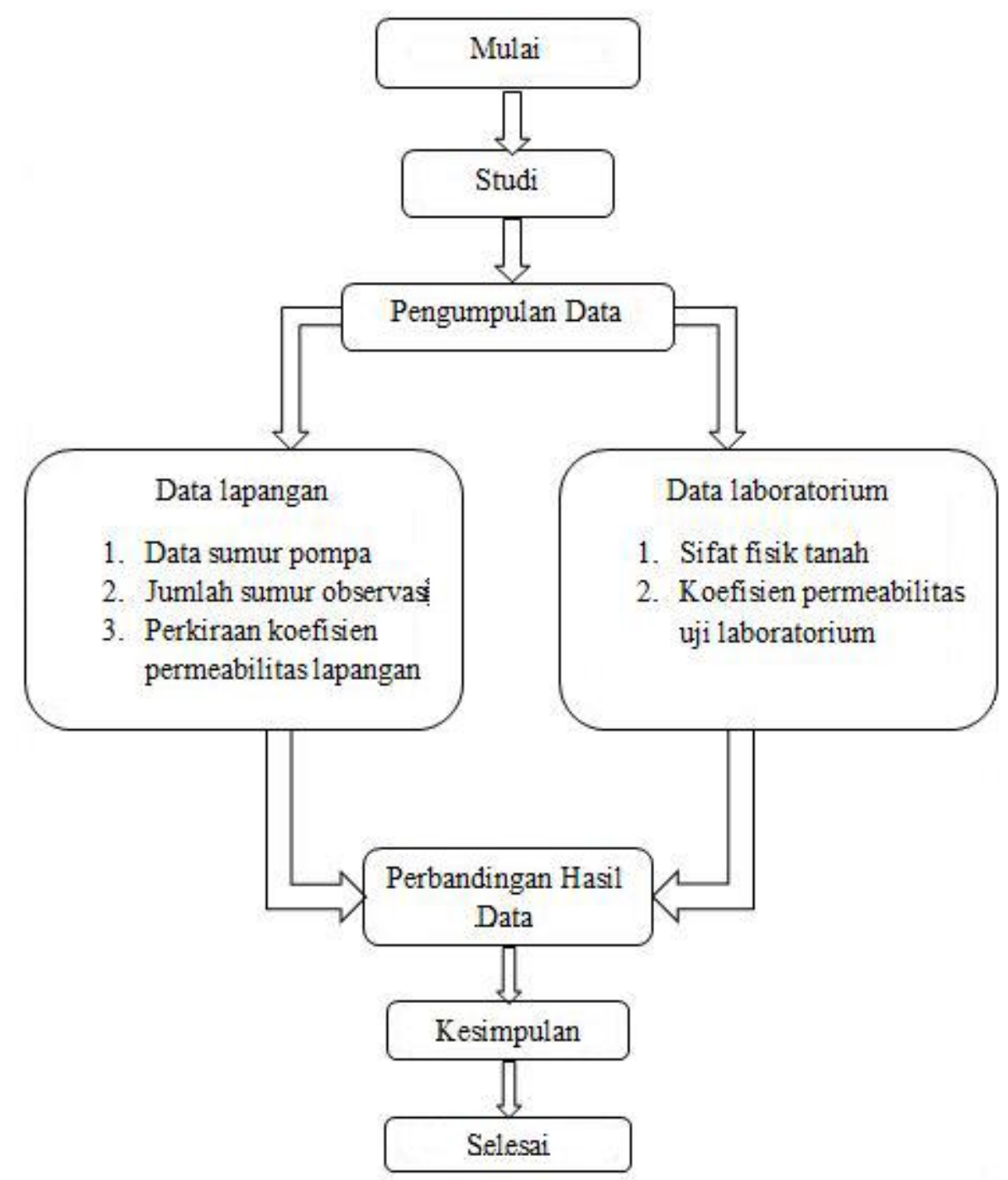

Gambar 4. Diagram alir penelitian

\section{PENGUJIAN DAN HASIL ANALISIS}

\section{Analisis pumping test akifer tertutup dengan metode Thiem (steady state)}

Metode Thiem (steady state) dapat di terapkan pada saat kondisi penurunan muka air tanah telah mencapai kondisi setimbang, kondisi penurunan muka air tanah yang telah setimbang berada pada saat menit ke-1520. Berdasarkan hasil perhitungan metode Thiem dapat diambil rentang nilai koefisien permeabilitas $(k)$ sebesar $0,02 \mathrm{~cm} /$ detik$0,06 \mathrm{~cm} /$ detik. Arah aliran air didalam proses pumping test ini bergerak secara horizontal gambar 5 . Hasil dalam bentuk grafik dapat dilihat pada gambar 6. 


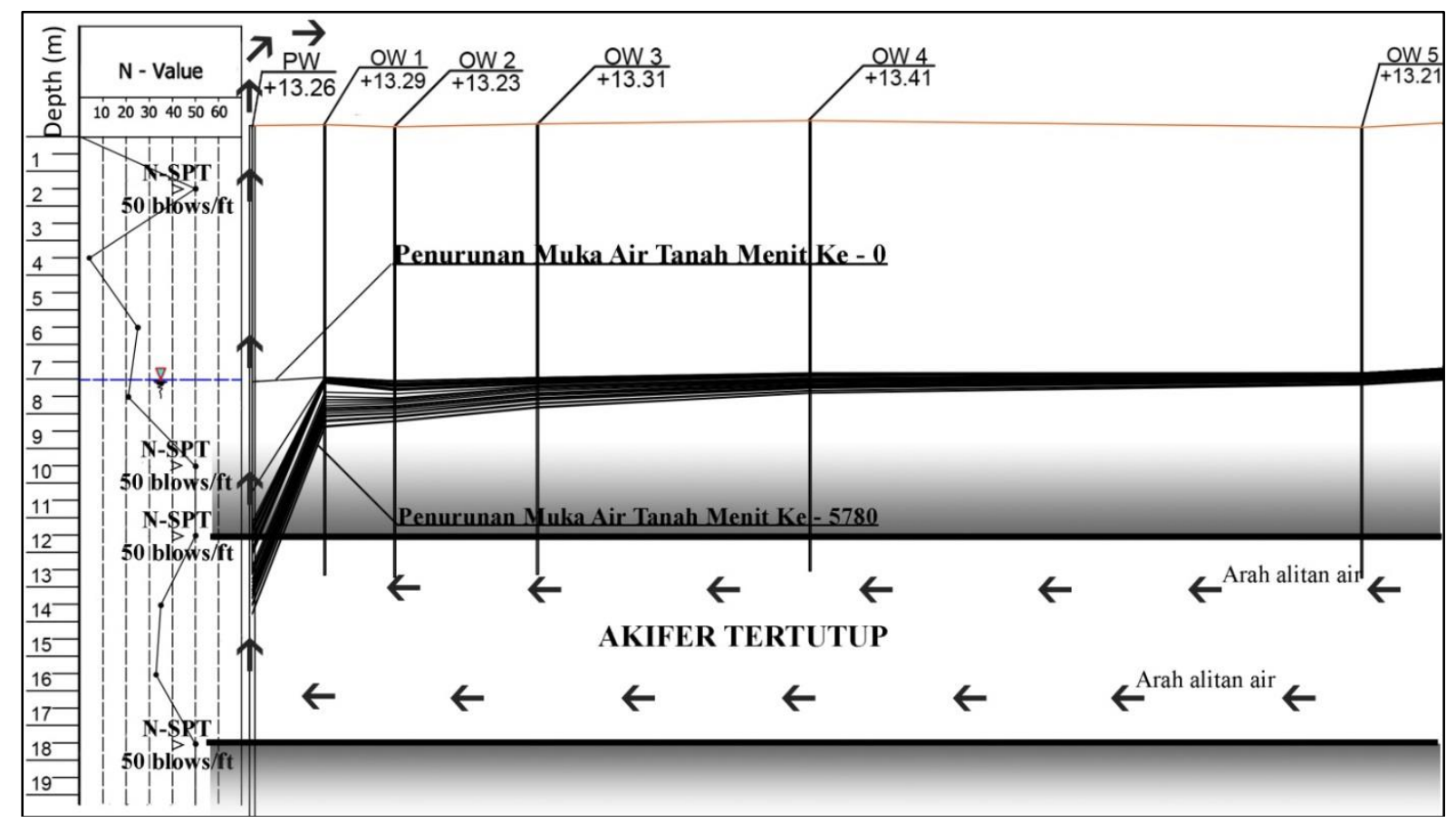

Gambar 5. Arah aliran air di dalam proses pumping test

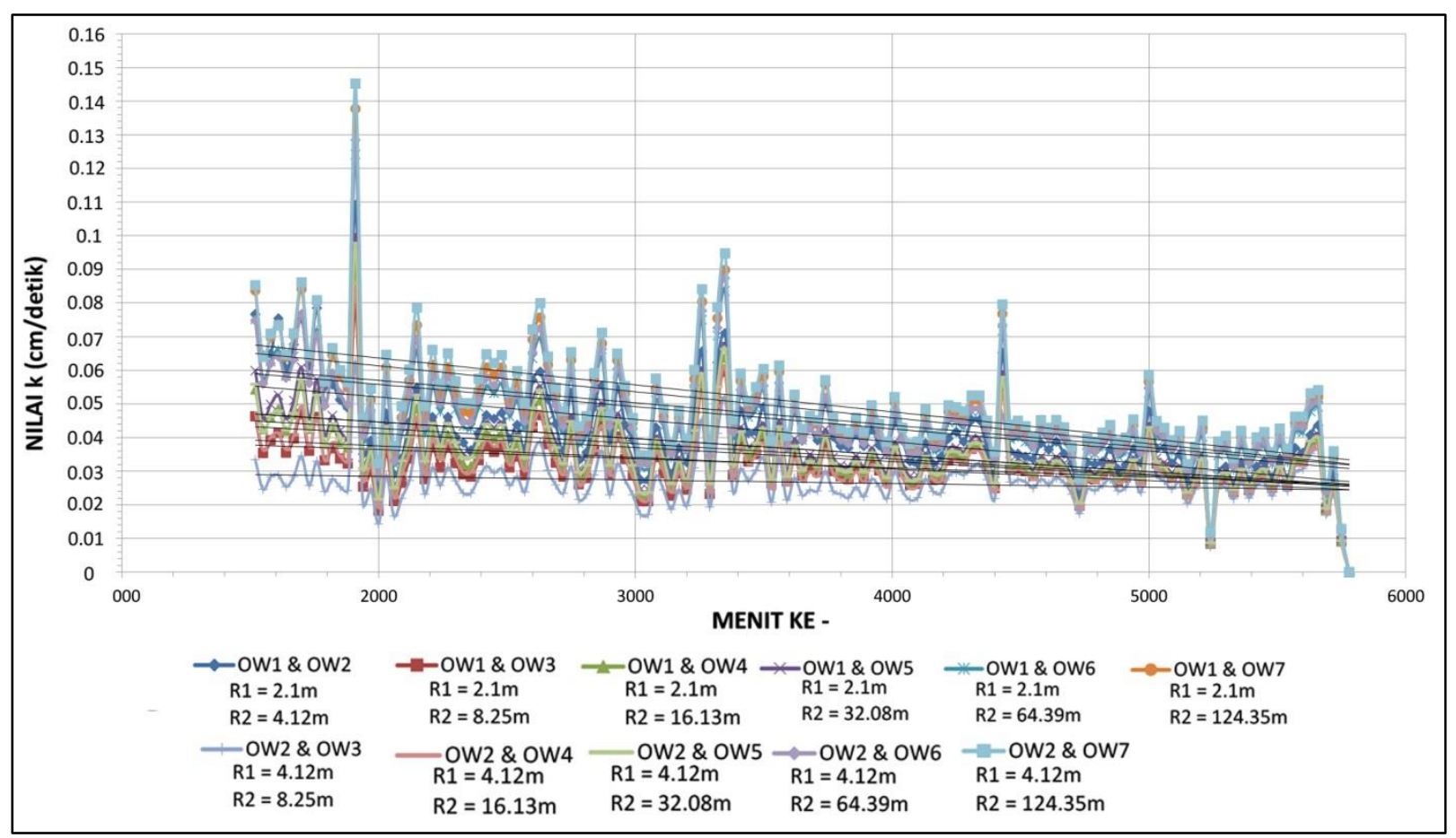

Gambar 6. Grafik rentang nilai koefisien permeabilitas $(k)$ dengan Metode Thiem

\section{Analisis pumping test akifer tertutup dengan metode Theis (Unsteady State)}

Metode Theis digunakan untuk akifer tertutup yang alirannya berada dalam keadaan tidak setimbang (unsteady state). Jika dalam metode Thiem, perhitungan dilakukan ketika penurunan muka air tanah telah mencapai keadaan seimbang (steady state) pada menit ke - 1520, maka dalam metode ini, kondisi tidak setimbang dapat diasumsikan terjadi sejak awal pemompaan (menit ke - 0) hingga pemompaan berakhir (menit ke - 5780). Berdasarkan hasil 
perhitungan metode Theis, dapat diambil rentang nilai koefisien permeabilitas (k) sebesar $6,03 \times 10^{-2} \mathrm{~cm} / \mathrm{detik}-$ $6,03 \times 10^{-3} \mathrm{~cm} /$ detik. Grafik rentang nilai koefisien permeabilitas dapat dilihat pada (Gambar 7).

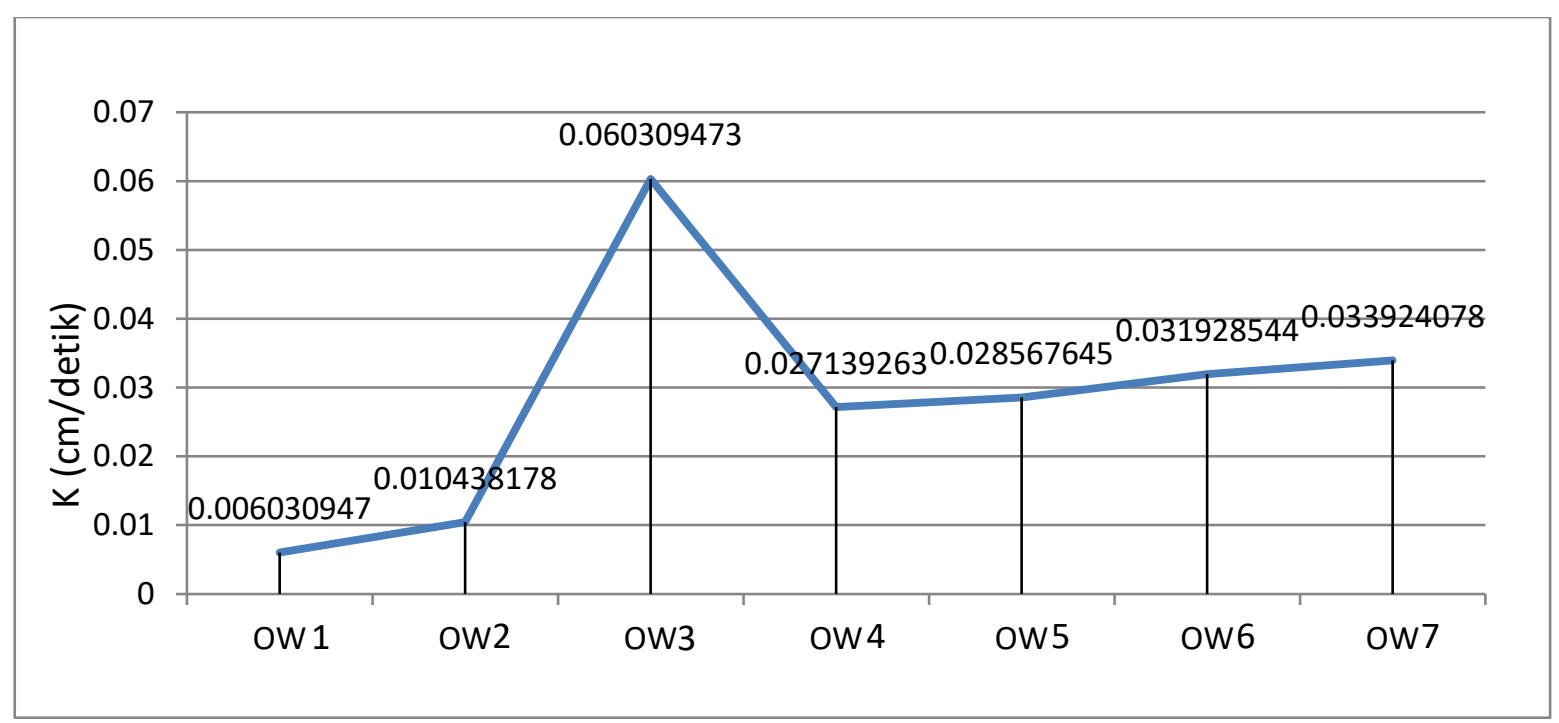

Gambar 7. Grafik rentang nilai koefisien permeabilitas (k) dengan Metode Theis

\section{Uji coba laboratorium dengan constant head permeameter}

Pengukuran nilai koefisien permeabilitas $(k)$ di laboratorium dilakukan dengan menggunakan parameter berat volume tanah $(\gamma)$. Sampel tanah diambil dari lokasi BH14 dan BH15 pada kedalaman 13m-14m, masing-masing sampel diuji dengan menggunakan rekayasa berat volume $\gamma_{\min }, \gamma, \gamma_{\max }$ pada sampel tanah. Uji permeabilitas constant head masing masing dilakukan uji coba sebanyak dua buah sampel untuk $\gamma_{\min }, \gamma, \gamma_{\max }$. Keseluruhan hasil pengujian nilai koefisien permeabilitas pada laboratorium dapat dilihat pada tabel 2 , dan grafik hasil pengujian terdapat pada gambar 8 .

Tabel 2. Nilai koefisien permeabilitas hasil uji laboratorium

\begin{tabular}{|c|c|c|c|c|c|}
\hline \multirow[t]{2}{*}{ Jenis Sampel } & \multicolumn{5}{|c|}{$\begin{array}{l}\text { Nilai Koefisien Permeabilitas (cm/detik) } \\
\text { Pada Pengukuran ke- }\end{array}$} \\
\hline & 1 & 2 & 3 & 4 & 5 \\
\hline $\mathrm{BH} 15 \gamma_{\min } 1$ & $6,84 \mathrm{E}-05$ & $6,92 \mathrm{E}-05$ & $6,63 \mathrm{E}-05$ & $6,58 \mathrm{E}-05$ & \\
\hline BH15 $\gamma_{\min } 2$ & $1,38 \mathrm{E}-04$ & $1,35 \mathrm{E}-04$ & $1,31 \mathrm{E}-04$ & $1,30 \mathrm{E}-04$ & \\
\hline $\mathrm{BH} 15 \gamma 1$ & $1,38 \mathrm{E}-04$ & $1,41 \mathrm{E}-04$ & $1,43 \mathrm{E}-04$ & $1,42 \mathrm{E}-04$ & \\
\hline BH15 $\gamma 2$ & $4,56 \mathrm{E}-05$ & $4,70 \mathrm{E}-05$ & 4,40E-05 & $4,74 \mathrm{E}-05$ & \\
\hline BH15 $\gamma_{\max } 1$ & $6,89 \mathrm{E}-05$ & $6,47 \mathrm{E}-05$ & $6,29 \mathrm{E}-05$ & $6,15 \mathrm{E}-05$ & \\
\hline BH15 $\gamma_{\max } 2$ & $5,21 \mathrm{E}-05$ & $5,54 \mathrm{E}-05$ & $5,58 \mathrm{E}-05$ & $5,34 \mathrm{E}-05$ & \\
\hline $\mathrm{BH} 14 \gamma_{\min } 1$ & $2,55 \mathrm{E}-06$ & 4,46E-06 & $4,00 \mathrm{E}-06$ & 3,77E-06 & 1,01E-06 \\
\hline $\mathrm{BH} 14 \gamma_{\min } 2$ & $2,09 \mathrm{E}-06$ & $2,09 \mathrm{E}-06$ & $2,13 \mathrm{E}-06$ & $8,76 \mathrm{E}-07$ & \\
\hline BH14 $\gamma 1$ & $1,13 \mathrm{E}-05$ & $1,02 \mathrm{E}-05$ & 9,35E-06 & $8,27 \mathrm{E}-06$ & \\
\hline $\mathrm{BH} 14 \gamma 2$ & 0 & 0 & 0 & 0 & \\
\hline BH14 $\gamma_{\max } 1$ & 0 & 0 & 0 & 0 & \\
\hline BH14 $\gamma_{\max } 2$ & 0 & 0 & 0 & 0 & \\
\hline
\end{tabular}




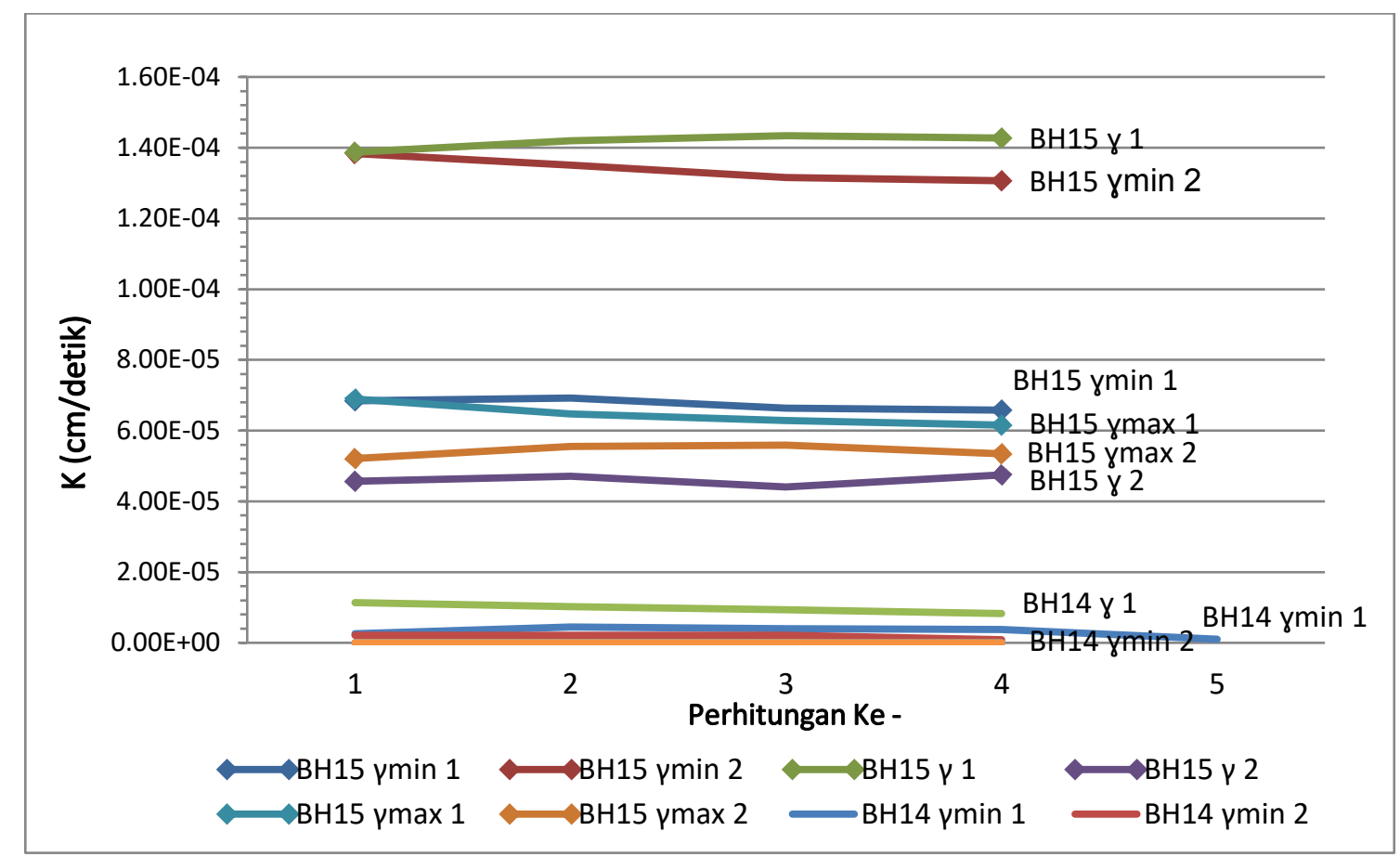

Gambar 8. Grafik rentang nilai koefisien permeabilitas $(k)$ hasil uji laboratorium

\section{Metode perhitungan dengan pendekatan rumus empiris Hazen}

Selain menggunakan melakukan uji pada lapangan dan laboratorium, nilai koefisien permeabilitas $(k)$ juda dapat diketahui menggunakan persamaan empiris yang dibuat oleh Hazen. Persamaan empiris tersebut menghubungkan permeabilitas dengan ukuran butir efektif $\left(D_{10}\right)$ dari suatu analisa saringan. Persamaan empiris biasanya digunakan untuk menentukan koefisien permeabilitas tanah $(k)$ dalam berbagai jenis sedimen dibeberapa sampel (Lopez, 2015). Sampel tanah yang dapat menunjukkan hasil butir efektif $\left(D_{10}\right)$ hanya terdapat pada sampel ke- 2 pada lokasi BH15. Perhitungan menggunakan nilai $\mathrm{C}=40$ dan nilai $\mathrm{C}=80$. Hasil rentang nilai koefisien permeabilitas $(k)$ yang didapat berdasarkan perhitungan metode empiris adalah berkisar antara 4,356 x $10^{-6} \mathrm{~cm} /$ detik sampai $8,712 \times 10^{-6}$ $\mathrm{cm} /$ detik. Hasil grafik dapat dilihat pada gambar 9 .

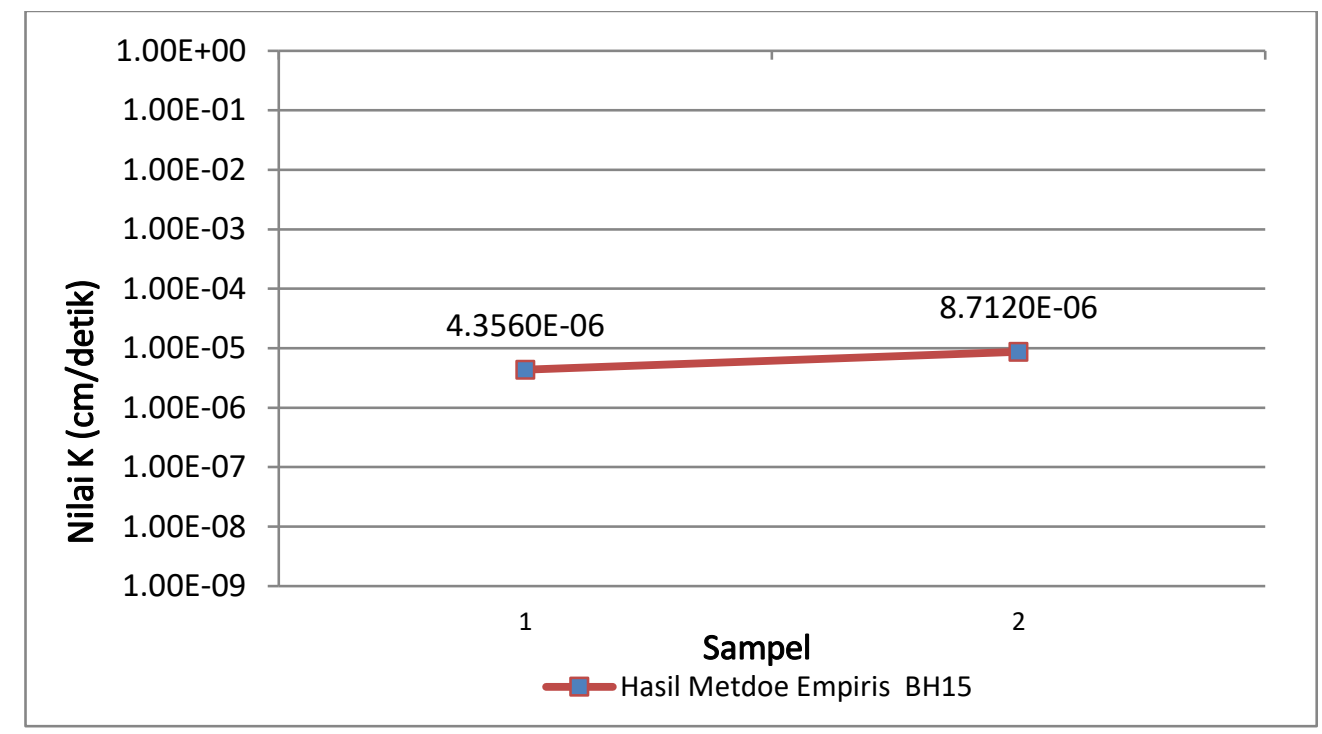

Gambar 9. Grafik rentang nilai koefisien permeabilitas (k) dengan Rumus Hazen 


\section{Analisa perbandingan nilai koefisien permeabilitas $(k)$}

Rasio perbandingan antara masing-masing hasil uji coba dapat dilihat pada tabel 3. dan grafik perbandingan dapat dilihat pada gambar 10 .

Tabel 3. Rasio perbandingan nilai koefisien permeabilitas

\begin{tabular}{|c|c|c|c|c|c|c|}
\hline \multicolumn{7}{|c|}{ Nilai Koefisien Permeabilitas $(k)(\mathrm{cm} /$ detik$)$} \\
\hline \multirow{2}{*}{$\begin{array}{c}\text { Lapangan } \\
\text { Metode } \\
\text { Thiem }\end{array}$} & \multirow{2}{*}{$\begin{array}{c}\text { Lapangan } \\
\text { Metode } \\
\text { Theis }\end{array}$} & \multirow{2}{*}{$\begin{array}{l}\text { Empiris } \\
\text { Metode } \\
\text { Hazen }\end{array}$} & \multirow{2}{*}{$\begin{array}{l}\text { Laboratorium } \\
\text { Constant head }\end{array}$} & \multicolumn{3}{|c|}{ Rasio perbandingan } \\
\hline & & & & Thiem - Lab & Theis - Lab & Hazen - Lab \\
\hline $6,8 \times 10^{-2}$ & $6,03 \times 10^{-2}$ & $8.71 \times 10^{-6}$ & $1,43 \times 10^{-4}$ & 474,21 & 420,57 & 0.06 \\
\hline- & - & - & - & - & - & - \\
\hline $2,8 \times 10^{-2}$ & $6,03 \times 10^{-3}$ & $4.35 \times 10^{-6}$ & $8,76 \times 10^{-7}$ & 31943,45 & 6880,33 & 4.96 \\
\hline
\end{tabular}

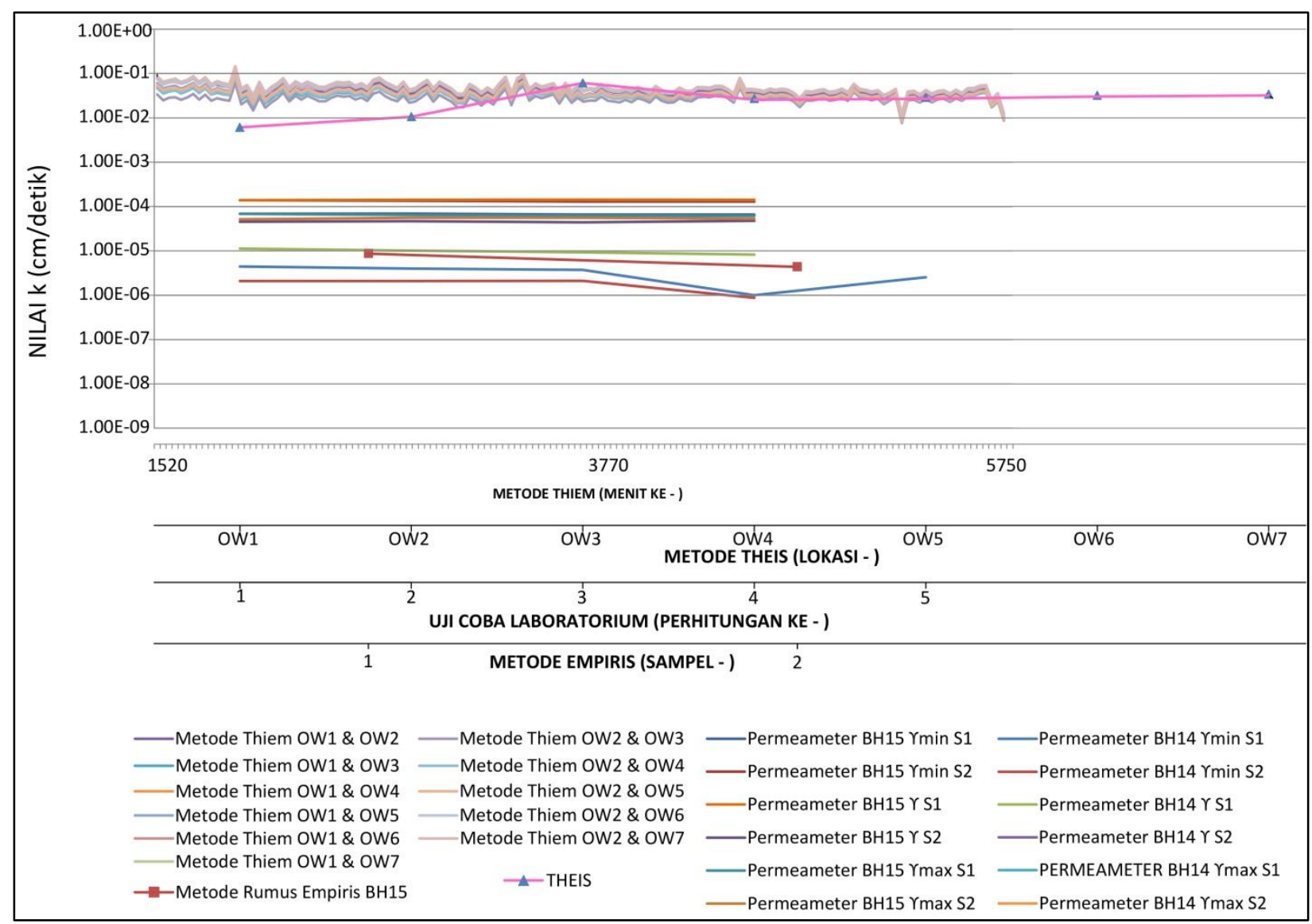

Gambar 10. Nilai koefisien permeabilitas $(k)$ dari berbagai metode

Dapat dilihat pada tabel 3 bahwa metode hazen memiliki rentang nilai koefisien permeabilitas $4,35 \times 10^{-6} \mathrm{~cm} / \mathrm{detik}$ sampai $8,71 \times 10^{-6} \mathrm{~cm} /$ detik, ini menghasilkan rasio perbandingan yang kecil terhadap metode uji coba laboratorium. Ini menandakan bahwa metode hazen lebih mendekati hasil pengujian laboratorium jika dibandingkan dengan metode lain. Hasil pengujian didalam laboratorium memiliki hasil yang lebih kecil dikarenakan arah air berjalan secara vertikal dalam menembus tanah, arah berjalan air secara vertikal menyebabkan air lebih sulit menembus lapisan tanah jika dibandingkan dengan uji coba dilapangan. 
Hasil yang didapat dari uji laboratorium memiliki nilai koefisien permeabilitas sebesar $1,43 \times 10^{-4} \mathrm{~cm} /$ detik sampai $8,76 \times 10^{-7} \mathrm{~cm} /$ detik. Ini menjadi hasil terkecil jika dibandingkan dengan metode-metode lain. Nilai koefisien permeabilitas pada uji lapangan (metode Thiem \& metode Theis) cenderung stabil pada rentang $10^{-2} \mathrm{~cm} / \mathrm{detik}$ sampai $10^{-3} \mathrm{~cm} /$ detik. Ini menghasilkan rasio perbandingan yang besar terhadap hasil uji coba laboratorium. Salah satu hal yang dapat menyebabkan nilai hasil uji laboratorium menjadi kecil adalah disebabkan oleh butir-butir tanah pada sampel cenderung sangat halus, sehingga menyebabkan air sulit untuk melewati sampel tanah pada permeameter. Nilai koefisien permeabilitas tanah sangat bergantung terhadap ukuran butir, distribusi bentuk dan kerapatan yang berfungsi sebagai penentu ukuran pori-pori yang ada di tanah (Ubani, 2018) .

\section{KESIMPULAN}

\section{Kesimpulan}

1. Berdasarkan Uji laboratorium, lokasi BH14 (lanau kelempungan) memiliki nilai koefisien permeabilitas sebesar $1,13 \times 10^{-5} \mathrm{~cm} /$ detik $-8,76 \times 10^{-7} \mathrm{~cm} /$ detik dan pada lokasi BH15 (pasir halus kelanauan) sebesar

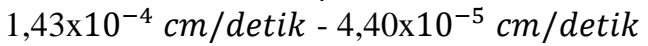

2. Berdasarkan rumus empiris Hazen, nilai koefisien permeabilitias (k) pada lokasi sampel tanah BH15 adalah berada pada rentang $4,35 \times 10^{-6} \mathrm{~cm} /$ detik sampai $8,71 \times 10^{-6} \mathrm{~cm} /$ detik.

3. Nilai koefisien permeabilitas (k) pada lokasi BH14 dan lokasi BH15 memiliki nilai koefisien permeabilitas berdasarkan hasil pumping test sebesar $6,8 \times 10^{-2} \mathrm{~cm} /$ detik $-2,8 \times 10^{-2} \mathrm{~cm} /$ detik dengan metode Thiem, dan sebesar $6,03 \times 10^{-2} \mathrm{~cm} /$ detik $-6,03 \times 10^{-3} \mathrm{~cm} /$ detik dengan metode Theis.

4. Nilai koefisien permeabilitas (k) dengan metode empiris Hazen, menghasilkan nilai yang paling mendekati hasil uji nilai koefisien permeabilitas (k) laboratorium. Yaitu berada pada rentang $4,35 \times 10^{-6} \mathrm{~cm} / \mathrm{detik}$ sampai $8,71 \times 10^{-6} \mathrm{~cm} /$ detik. Sedangkan nilai hasil uji laboratorium adalah $1,43 \times 10^{-4} \mathrm{~m} /$ detik sampai $8,76 \times 10^{-7}$ $\mathrm{m} /$ detik.

5. Rasio perbandingan antara nilai koefisien permeabilitas $(k)$ metode Hazen dan Uji laboratorium adalah yang paling kecil diantara metode lainnya.

\section{Saran}

1. Rekayasa kepadatan tanah dalam proses uji coba permeameter constant head sangat berpengaruh terhadap hasil nilai koefisien permeabilitas, karena dalam uji coba permeameter constant head hanya mengandalkan gravitasi sebagai tekanannya. Maka data-data pendukung yang lengkap dibutuhkan untuk mendapatkan hasil yang optimal.

2. Penggunaan alat yang sesuai dengan standar akan menghasilkan data yang valid.

3. Data-data pendukung yang memadai akan sangat membantu dalam menghasilkan data yang valid saat melakukan penelitian.

4. Sampel tanah yang memadai dibutuhkan dalam melakukan uji coba di laboratorium. Banyak tanah yang akan terbuang saat melakukan uji coba, jika sampel tanah memadai maka uji coba dapat berjalan dengan baik tanpa kekurangan sampel tanah.

5. Selain sampel disturbed, sebaiknya sampel undisturbed juga tersedia agar penelitian yang dilakukan menghasilkan data yang valid.

\section{DAFTAR PUSTAKA}

ASTM Standard D2434-68. Standard Test Method for Permeability of Granular Soils (Constant Head). Pennsylvania: ASTM International, 2006

Bowles, J.E. Physical And Geotechnical Properties Of Soil. Singapore: Mc-Graw Hill, 1979.

Das, B.M. Advanced Soil Mechanics. New York: Taylor \& Francis, 2008

Hubbert, M.K. "Darcy's Law And The Field Equations Of The Flow Of Underground Fluids". Hydrological Sciences Journal. vol. 2, no. 1, 1957, pp. 23-59.

Kruseman, G.P. and N.A. de Ridder. Analysis and Evaluation of Pumping Test Data. Second Edition, ILRI Publication 47, International Institute for Land Reclamation and Improvement (ILRI), The Netherlands: Wageningen, 2000.

Lopez, O.M., et al. "Method of Relating Grain Size Distribution to Hydraulic Conductivity in Dune Sands to Assist in Assessing Managed Aquifer Recharge Projects: Wadi Khulays Dune Field, Western Saudi Arabia”. Water, vol. 7, 2015, pp. 6411-6426.

Mays, L.W. Ground and Surface Water Hydrology. New York: John Wiley and Sons, 2012. 
Theis, C.V. "The relation between the lowering of the piezometric surface and the rate and duration of discharge of a well using groundwater storage”. Trans. Amer. Geophys. Union, vol. 16, no. 5, 1938, pp. 19-524.

Thiem, G. Hydrologische Methoden. Gebhardt, Leipzig, 56. 1906.

Ubani, C.E., G.O. Ani, and T.T. Womiloju. "Permeability Estimation Model From Grain Size Sieve Analysis: Data Of Onshore Central Niger Delta”. European Journal of Engineering Research and Science, vol. 3, no. 12, December 2018, pp. 119-125. 